\title{
Potensi Reproduksi, Pola Pemijahan Serta Alternatif Pengelolaan Ikan Kembung Laki-Laki (Rastrelliger kanagurta) Di Sekitar PesisirTimur Perairan Biak
}

\author{
Bernhard Katiandagho ${ }^{1}$, Fatmawaty Marasabessy ${ }^{1 *}$ \\ 1Staf Pengajar Prodi PSP, APK-Biak, Email: katiandagho_bernhard@yahoo.com \\ * Koresponden Author
}

\begin{abstract}
ABSTRAK
Penelitian ini bertujuan untuk mengetahui jenis pemanfaatan dan menganalisa nilai ekonomi hutan mangrove di Desa Mare Kofo Kota Tidore Volume produksi ikan kembung yang meningkat mendorong para pelaku perikanan mengeksploitasi tanpa memperhatikan keberadaan dan keberlanjutannya, disertai adanya upaya penambahan penangkapan ikan kembung secara terus menerus dapat berdampak terhadap terjadinya penurunan stok ikan kembung. Penelitian ini dilakukan dengan tujuan menganalisis Potensi reproduksi, Pola pemijahan, dan alternatif pengelolaan. penelitian ini dilaksanakan dari Bulan Januari sampai dengan Juni 2018 di sekitar Perairan Timur Pulau Biak menggunakan jenis alat tangkap Mini Purse Seine. Analisa data dilakukan terhadap tingkat kematangan gonad, Fekunditas, dan sebaran diameter telur, Dari hasil yang telah dikemukakan diatas, maka dapat ditarik kesimpulan Potensi reproduksi (fekunditas) berkisar antara 70.680 - 699.60 butir telur yang terdapat pada selang kelas ukuran panjang 267 - 303 mm. Pola pemijahan ikan kembung lelaki bersifat total Spawning yaitu pemijahan yang berlangsung dalam waktu panjang. alternatif pengelolaan yang dapat dilakukan adalah mengatur waktu penangkapan yaitu tidak melakukan penangkapan berlebih pada waktu puncak pemijahan yaitu bulan April - Juni. ikan yang seharusnya boleh ditangkap adalah ikan jantan maupun betina yang ukurannya melebihi panjang $292 \mathrm{~mm}$. agar bisa diberi kesempatan untuk memijah sehingga populasi R. kanagurta dapat lestari.
\end{abstract}

Kata Kunci : Potensi Reproduksi, Pola Pemijahan

\section{PENDAHULUAN}

1.1 Latar Belakang

Ikan kembung laki-laki (R. kanagurta) merupakan komoditas perikanan penting yang diminati banyak orang untuk dikonsumsi dalam pemenuhan gizi sehari-hari karena harganya yang murah dan gizinya yang cukup tinggi serta menjadi komoditi utama bagi rakyat (skala kecil). Tingginya minat masyarakat terhadap R.kanagurta mendorong banyak pelaku perikanan untuk mengeksploitasi sumberdaya ini tanpa memperhatikan keberlanjutan dari kegiatan tersebut. eksploitasi ikan kembung lelaki diupayakan secara intensif dengan tehnik 'berburu' sehingga dari tahun ke tahun semakin berkurang. Di sepanjang perairan timur Pulau Biak, jenis perikanan yang memiliki taktik berburu tersebut berupa jaring insang dan pukat cincin (purse seine).

Eksploitasi yang terus menerus tanpa memperhatikan keberlanjutannya dapat menyebabkan penurunan kualitas dan kuantitas sumberdaya yang secara tidak langsung mampu menyebabkan kepunahan spesies. Keberlanjutan kesediaan ikan ditentukan oleh potensi pertumbuhan dan reproduksi ikan tersebut (Suwarso et al., 2007). Jumlah produksi ikan R. kanagurta dari tahun ke tahun menurut data statistika DKP Propinsi Papua mengalami kenaikan dari 15.855 ton (2015) menjadi 32.422 ton (2016). Begitu juga dengan tingkat eksploitasi menggunakan alat tangkap mini purse seine dari tahun 167 
jumlahnya sebesar 254 buah terus meningkat hingga tahun 2016 mencapai 405 buah (DKP Propinsi Papua, 2016).

Volume produksi ikan kembung yang meningkat mendorong para pelaku perikanan mengeksploitasi sumberdaya ikan kembung yang ada tanpa memperhatikan keberadaan dan keberlanjutannya, disertai adanya upaya penambahan penangkapan ikan kembung secara terus menerus dikhawatirkan akan menyebabkan penangkapan berlebih hingga terjadinya penurunan stok ikan kembung.

Menurut Mahyuddin (2012), Penurunan populasi R.kanagurta dapat disebabkan oleh degradasi kualitas lingkungan pesisir, termasuk pencemaran perairan akibat aktivitas manusia, kegiatan perikanan yang merusak, penangkapan ikan berlebih dan dilakukan secara tidak sah baik oleh pelaku dalam negeri maupun pihak asing di Indonesia. Penurunan sumberdaya ikan dapat mengakibatkan Indonesia kesulitan dalam meningkatkan produksi secara nyata melalui kegiatan perikanan tangkap.

1.2 Tujuan dan Kegunaan Penelitian

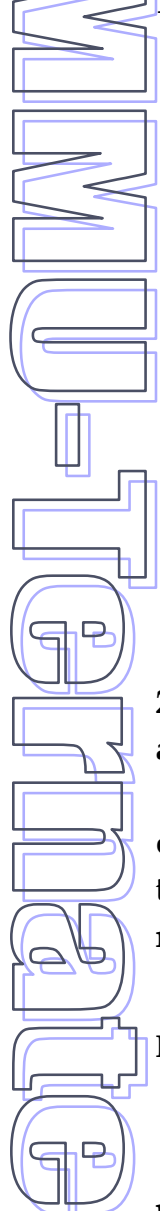

\subsection{Analisis Data}

a. Indeks Kematangan Gonad (IKG)

Indeks Kematangan Gonad (IKG) dianalisa berdasarkan berat gonad dan berat tubuh ikan contoh dengan menggunakan rumus sebagai berikut (Effendie 1997) :

$$
\mathrm{IKG}=\frac{B_{g}}{B_{t}} \times 100
$$

Keterangan :

IKG = Indeks Kematangan Gonad (\%)

Bg = Berat gonad (gram)

Bt = Berat tubuh (gram)

b. Fekunditas
Penelitian ini bertujuan untuk menganalisis Potensi reproduksi, Pola pemijahan, dan alternatif pengelolaan. Penelitian ini diharapkan dapat memberikan beberapa informasi terkait biologi reproduksi ikan kembung laki-laki (Rastrelliger kanagurta) diantaranya nisbah kelamin, ukuran pertama kali matang gonad, pendugaan waktu pemijahan, potensi reproduksi, serta pola pemijahan yang merupakan sebagian dari unsur-unsur yang perlu dipertimbangkan dalam rencana pengelolaan perikanan ikan kembung di sekitar perairan timur Pulau Biak agar dapat dimanfaatkan secara optimal dan berkesinambungan.

\section{METODE PENELITIAN}

\subsection{Waktu dan Tempat Penelitian}

Ikan contoh yang digunakan dalam penelitian ini diperoleh dari nelayan yang beroperasi di sekitar Perairan Pesisir Timur Pulau Biak menggunakan jenis alat tangkap Mini Purse Seine . Pengambilan ikan contoh dimulai dari bulan Januari sampai Juni 2018 dan analisa ikan dilakukan di laboratorium Akademi Perikanan Kamasan Biak.

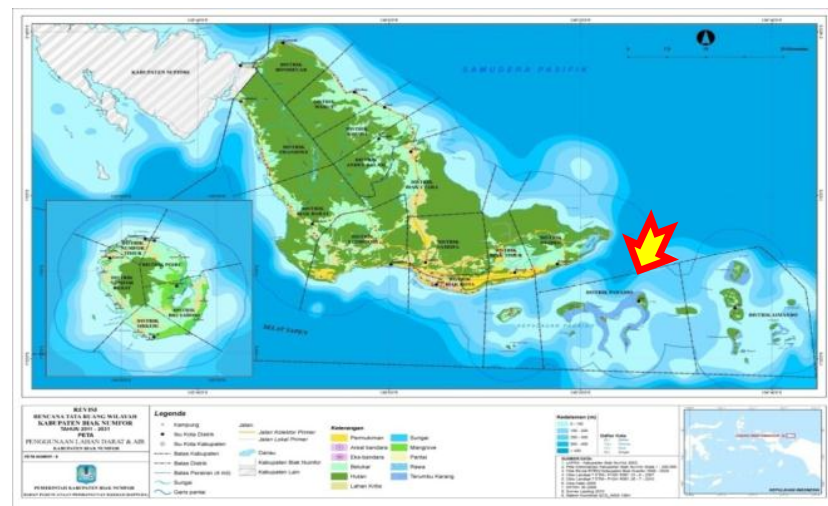

Keterangan :

$\mathbf{F}=$ Fekunditas

$\mathrm{G}=$ Berat gonad total (gram)

$\mathrm{V}=$ Isi pengenceran $(\mathrm{cc})$

$X=$ Jumlah telur tiap cc

$\mathrm{Q}=$ Berat gonad contoh (gram)

Sedangkan analisis hubungan fekunditas dengan panjang total tubuh menggunakan rumus sebagai berikut (effendi 1997) : 


$$
\mathrm{F}=\boldsymbol{a} \mathrm{L}^{\mathrm{b}}
$$

Keterangan :

$\begin{aligned} \text { Keterangan : } & =\text { Fekunditas (butir) } \\ \mathrm{L} & =\text { Panjang total ikan }(\mathrm{mm}) \\ \mathrm{a} \text { dan } \mathrm{b} & =\text { Konstanta }\end{aligned}$

Persamaan diatas dapat ditransformaskan ke logaritma yang akan didapat persamaan regresi garis lurus, yaitu :

Keterangan :

$$
\log \mathrm{F}=\log a+b \log \mathrm{L}
$$

$$
\begin{array}{ll}
\mathrm{F} & =\text { Fekunditas ikan } \\
\log \mathrm{F} & =\mathrm{y} \\
\log 1 & =\mathrm{x}
\end{array}
$$

Log a dan b sebagai intersep dan slope yang dapat dihitung dengan menggunakan rumus :

$$
\begin{gathered}
b=\frac{\left(n \sum x y-\sum x-\sum y\right)}{\left(n \sum x^{2}-\left(\sum x\right)^{2}\right)} \\
\alpha=y-b x
\end{gathered}
$$

Keeratan hubungan antara panjang dengan fekunditas dilihat dari koefisien korelasi r, yaitu :

$$
r=\frac{\left[\sum x y-\left(\sum x\right)-\left(\sum y\right)\right]}{\sqrt{\left.\left.\left[n \sum x^{2}-\left(\sum x\right)^{2}\right)\left(n \sum y^{2}-\left(\sum x\right)^{2}\right)\right]^{\frac{1}{2}}\right]}}
$$

\section{c. Sebaran Diameter Telur}

Diameter telur merupakan garis tengah atau ukuran panjang dari suatu telur yang

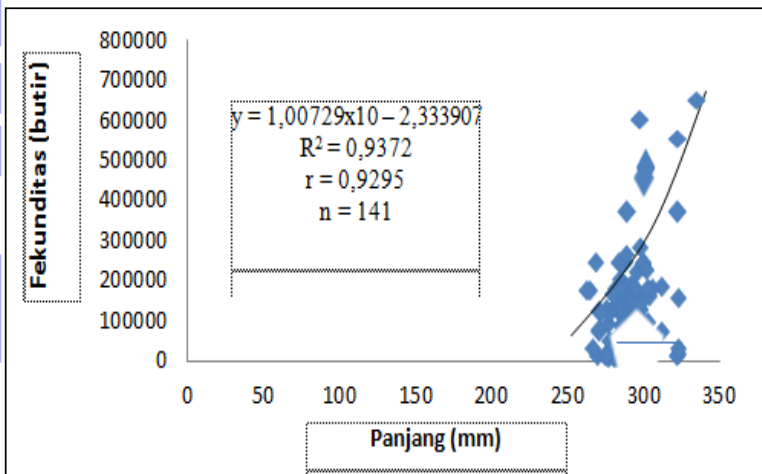

Gambar 1. Hubungan fekunditas dengan panjang dan berat R. kanagurta betina TKG IV di sekitar perairan timur Biak.

Berdasarkan hasil pengamatan terhadap hubungan antara fekunditas dengan panjang total R. kanagurta didapatkan persamaan $\mathrm{y}=$ 1,00729x10 - 2,333907. Dan diperoleh koefisien determinasi $\left(R^{2}\right)$ sebesar 0,9372 yang menunjukkan bahwa hanya $93,72 \%$ dari keragaman nilai fekunditas R. kanagurta dapat dijelaskan oleh panjang total ikan. Koefisien korelasi (r) diperoleh sebesar 0,9295 yang menunjukkan bahwa hubungan antara

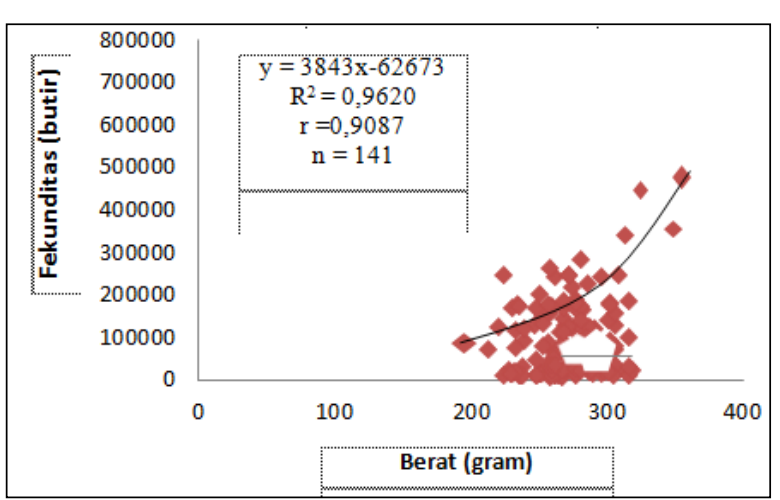

diukur dengan mikrometer berskala yang sudah ditera (Effendie, 1979). Ukuran diameter telur digunakan untuk melihat kuantitas telur. Diameter telur dapat dihitung dengan menggunakan rumus sebagai berikut (Rodriquez et al., 1995) :

$$
\mathrm{Ds}=\sqrt{D x d}
$$

Dimana :

Ds = Diameter telur sebenarnya $(\mathrm{mm})$

D = Diameter telur secara horizontal $(\mathrm{mm})$

$\mathrm{D}=$ Diameter telur secara vertikal $(\mathrm{mm})$.

Pola pemijahan dihitung berdasarkan data sebaran diameter telur dan untuk lebih jelasnya dibuat grafik hubungan antara sebaran diameter telur dan frekuensinya. Sebaran frekuensi tersebut akan menentukan tipe pemijahan ikan, apakah ikan termasuk total spawner atau partial spawner.

\section{HASIL DAN PEMBAHASAN}

\subsection{Potensi Reproduksi}

Potensi reproduksi dapat diduga melalui jumlah telur yang masak sebelum dikeluarkan pada waktu ikan memijah atau merupakan fekunditas. Fekunditas dihitung pada ikan betina dengan TKG IV.

fekunditas dengan panjang total adalah erat. Bila dihubungkan fekunditas ikan dengan panjang ikan maka diketahui rata-rata fekunditas yang paling sedikit terdapat pada selang kelas ukuran panjang $2676-282 \mathrm{~mm}$ yaitu 70.680 butir telur. Seiring dengan meningkatnya ukuran panjang ikan maka ditemukan fekunditas yang besar yaitu $\mathbf{6 9 9 . 6 0 0}$ butir telur yang terdapat pada selang kelas ukuran panjang 297-303 mm. 
Selanjutnya dari hasil pengamatan, hubungan antara fekunditas dengan berat total $R$. kanagurta didapatkan persamaan $y=3843 x$ 62673. dan diperoleh koefisien determinasi (R2) sebesar 0,9620 yang menunjukkan bahwa hanya $98,20 \%$ dari keragaman nilai fekunditas $R$. kanagurta dapat dijelaskan oleh berat total ikan. Koefisien korelasi (r) diperoleh sebesar 0,9087 yang menunjukkan bahwa hubungan antara fekunditas dengan berat total adalah erat. Bila dihubungkan fekunditas ikan dengan berat ikan maka diketahui rata-rata fekunditas yang paling sedikit terdapat pada selang kelas ukuran berat 263-269 gram yaitu 64.965 butir telur. Seiring dengan meningkatnya ukuran berat ikan maka ditemukan fekunditas yang besar yaitu 692.139 butir telur yang terdapat pada selang kelas ukuran berat 297-303- gram.

\subsection{Pola Pemijahan}

Sebaran diameter telur dapat mengindikasikan pola pemijahan ikan. Ada dua tipe pola pemijahan, yaitu total spawning dan partial spawning. Ovarium ikan yang mengandung telur masak berukuran sama semua atau seragam menunjukkan waktu pemijahan yang pendek. Sebaliknya, waktu pemijahan yang panjang dan terus menerus ditandai oleh banyaknya ukuran telur ikan yang berbeda didalam ovarium (Hoar 1963 in Lumbanbatu, 1979).
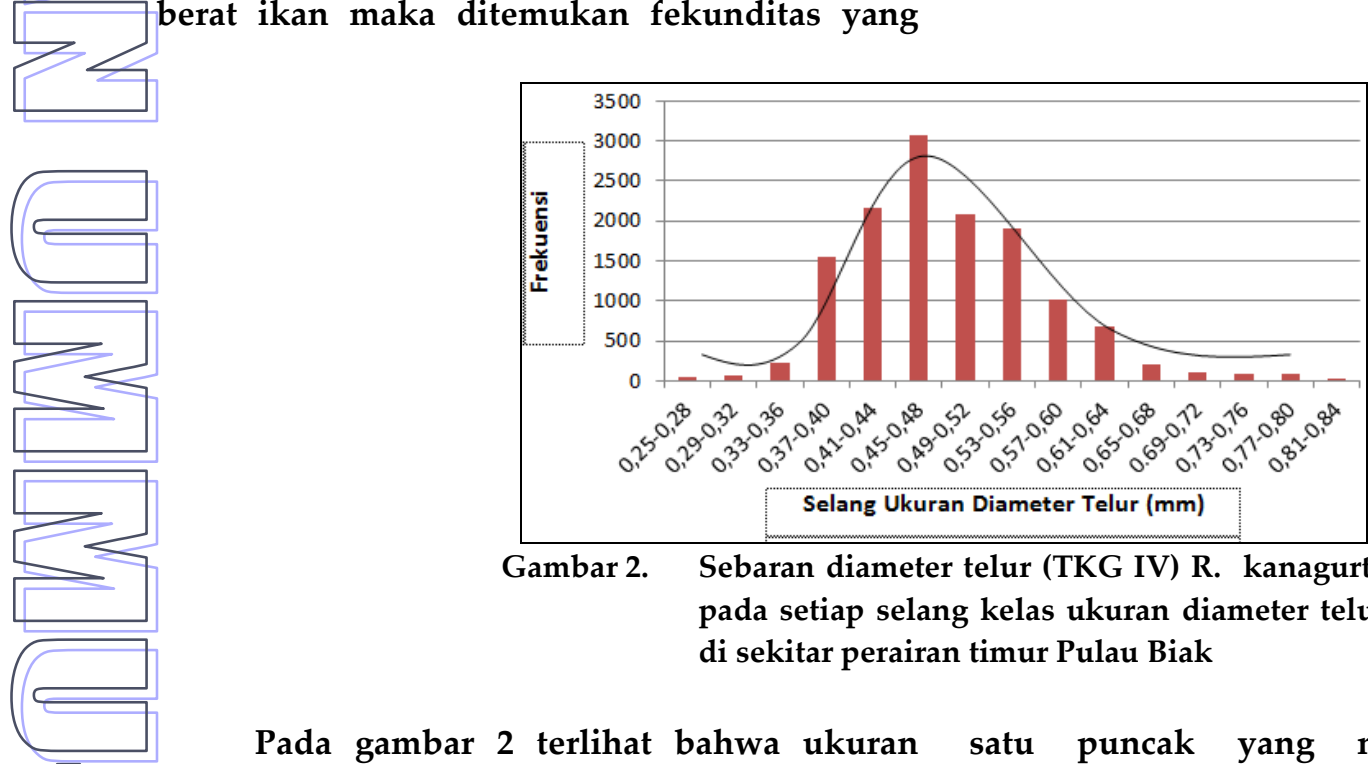

Gambar 2. Sebaran diameter telur (TKG IV) R. kanagurta pada setiap selang kelas ukuran diameter telur di sekitar perairan timur Pulau Biak

Pada gambar 2 terlihat bahwa ukuran dimaeter telur yang mempunyai TKG IV adalah beragam, ukuran diameter terkecil sebesar 0,25 $\mathrm{mm}$. Banyaknya ukuran diameter telur yang berbeda dalam ovarium ikan yang mengandung telur masak menunjukkan waktu pemijahan yang panjang dan terus menerus (Hoar in Lumbanbatu, 1979). Puncak tertinggi sebaran diameter telur ikan ini terdapat pada selang kelas $0.45-0.48 \mathrm{~mm}$. Dari sebaran diameter telur terdapat satu puncak yang menunjukkan bahwa R.kanagurta termasuk kedalam kelompok ikan total spawner yang berarti ikan memijah tidak bertahap dimana ikan memijah secara menyeluruh (Effendie, 2002). Hal ini sama dengan penelitian Safarini (2013) diameter telur R. kanagurta dari perairan Teluk Banten berada pada selang kelas 0.05$1.08 \mathrm{~mm}$. Puncak tertinggi sebaran diameter telur ikan ini terdapat pada selang kelas 0.21$0.28 \mathrm{~mm}$. Dari sebaran diameter telur terdapat satu puncak yang menunjukkan bahwa R.kanagurta termasuk kedalam kelompok ikan total spawner.

\subsection{Alternatif Pengelolaan}

Ikan kembung lelaki (Rastrelliger kanagurta) ialah ikan pelagis kecil dan neritik di sekitar perairan timur pulau Biak. R. kanagurta merupakan ikan yang memiliki nilai ekonomis penting dan merupakan bahan konsumsi masyarakat setempat. Harganya yang relatif terjangkau dan rasanya yang lezat menjadikan ikan kembung lelaki ini diminati oleh masyarakat sehingga penangkapan ikan ini terus menerus dilakukan setiap waktu. Hal ini dikhawatirkan akan mengurangi jumlah populasi R. kanagurta di alam khususnya disekitar perairan timur Pulau Biak. Oleh karena itu diperlukan pengelolaan yang tepat agar sumberdaya $R$. kanagurta dia alam dapat berlanjut. Pengelolaan yang dimaksud seperti 


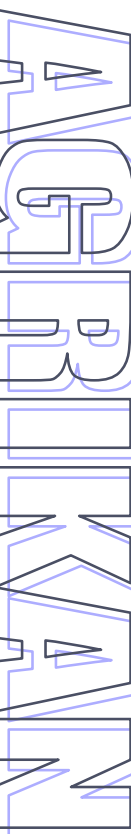

pengaturan waktu penangkapan maupun jenis dan ukuran yang diperbolehkan ditangkap.

Beberapa alternatif pengelolaan yang dapat dilakukan adalah mengatur waktu penangkapan yaitu tidak melakukan penangkapan berlebih pada waktu puncak pemijahan yaitu bulan April-Juni sehingga ikan-ikan yang matang gonad tidak banyak tertangkap agar proses pemijahan tidak terganggu. Ukuran pertama kali matang gonad $R$. kanagurta jantan maupun betina menurut perhitungan menggunakan metode SpearmanKarber ialah pada selang kelas ukuran panjang 285-292 mm. Sehingga dapat disimpulkan bahwa ikan yang seharusnya boleh ditangkap

adalah ikan jantan maupun betina yang ukurannya melebihi panjang $292 \mathrm{~mm}$. agar bisa diberi kesempatan untuk memijah sehingga populasi R. kanagurta dapat lestari.

\section{PENUTUP}

Dari hasil yang telah dikemukakan diatas, maka dapat ditarik kesimpulan Potensi reproduksi (fekunditas) berkisar antara 70.680 699.60 butir telur yang terdapat pada selang kelas ukuran panjang 267-303 $\mathrm{mm}$. Pola pemijahan ikan kembung lelaki bersifat total Spawning yaitu pemijahan yang berlangsung dalam waktu panjang

\section{DAFTAR PUSTAKA}

Dinas Kelautan dan Perikanan Provinsi Papua. 2016. Statistik Perikanan Daerah

Effendie M I. 1979. Metoda biologi perikanan. Cetakan Pertama. Yayasan Dewi Sri. Bogor. 112 hlm.

Effendie MI. 1997. Biologi Perikanan. Yayasan Pustaka Nusantara. Yayasan Pustaka Nusantama. Yogyakarta.163 hal.

Effendie, M. I. 2002. Biologi perikanan. Yayasan Pustaka Nusantara. Yogyakarta.

Lumbanbatu DTF. 1979. Aspek biologi reproduksi beberapa jenis ikan di waduk Lahor, Jawa Timur. Karya ilmiah. Fakultas Perikanan, Institut Pertanian Bogor. Bogor. Tidak dipublukasikan. $169 \mathrm{p}$.

Mahyuddin B. 2012. Kebutuhan teknologi untuk pengembangan penangkapan ikan. Di dalam : Pengelolaan Sumber daya Kelautan berbasis IPTEKS untuk,

Kemakmuran Bangsa. Seminar Nasional Kelautan VIII [Internet]; 2012 Mei ; Surabaya, Indonesia. Bogor (ID) : BBPPI. [diunduh Mei 2016]. Tersedia pada : http://bbppi.info/files/Makalah-KaBalai.pdf

Rodriquez, J. N., Z.J. Oteme and S. Hem. 1995.Comparative study of Vitellogenesis oftwo African catfish Chrysichthysnigrodigitatus and Heterobranchuslongifilis (clriidae). Aquat. Livingresour. 8 : 291-296.

Safarini, D. 2013. Potensi reproduksi ikan kembung lelaki (Rastrelliger kanagurta Cuvier 1817) dari Perairan Teluk Banten, Kabupaten Serang. Departemen Manajemen Sumberdaya Perairan. Fakultas Perikanan dan Ilmu Kelautan. Institut Pertanian Bogor. Bogor.

Suwarso, Hariati T, Ernawati T. 2007. Biologi reproduktif, preferensi habitat pemijahan dan dugaan stok pemijahan ikan kembung (Rastrelliger kanagurta, Fam. Scombridae) di Pantai Utara Jawa. Program Insentif Peningkatan Kemampuan Peneliti dan Perekayasa. Badan Riset Perikanan Laut.

Tangke U. 2014. Pemantaun Parameter Dinamika Populasi Ikan Kembung (Rastrelliger sp) Di Perairan Pesisir Pulau Ternate Provinsi Maluku Utara. Jurnal Ilmiah agribisnis dan Perikanan (agrikan UMMU-Ternate) Volume 7 Edisi 2 (Oktober 2014). 